\title{
G20 Presidency of Indonesia: Collective and Inclusive Agendas for World Development
}

\author{
Mohammed Ali Berawi ${ }^{*}$ \\ ${ }^{1}$ Faculty of Engineering, Universitas Indonesia, Kampus UI Depok, Depok 16424, Indonesia
}

The Group of Twenty (G20), comprised of 19 countries and the European Union, is an intergovernmental forum for addressing issues on global economic, financial stability, climate change mitigation, and sustainable development. The collective collaboration from industrialized nations and nations with emerging economies plays an important role in ensuring the achievement of inclusive economic development and sustainable development. Currently, the G20 Presidency of Indonesia focuses on three main agendas: (1) Global Health Architecture; (2) Sustainable Energy Transition; and (3) Digital Transformation. Indonesia highlights the importance of concrete and holistic actions among nations to stimulate prosperous economic growth and sustainable development across the globe. Continuing my previous editorial notes discussion, I will discuss these three G20 agendas.

The first agenda has shown how the COVID-19 pandemic is negatively affecting global economic growth, slowing down business activities, reducing production, and increasing unemployment and income uncertainty. Less investment, job losses, and disrupted national and global trade and supply chains have caused many governments collaborate and take necessary actions to enable a robust global recovery. The responses to COVID-19 have also prompted a strong drive to reduce inequal access to, and the quality of, public education and health facilities supported by government policies to increase country's resilience. These mitigating actions are required at the national and international levels. Furthermore, this drive will prompt stronger support for small- and medium-sized enterprises (SMEs) through business incubators and start-up companies to ensure urban economic resilience.

Thus, strengthening knowledge-sharing and collaboration among stakeholders in international contexts, such as the G20 forum, is needed to tackle the pandemic. Global coordination and cooperation are required to mitigate the spread of the pandemic and diminish its impact on economic and social stability. Moreover, this first agenda highlights the importance of strengthening the post-COVID-19 global health architecture, including the need for inclusive vaccine development and distribution and mobilization of global health financing.

Regarding the second agenda, the energy system is experiencing rapid transitions that are triggered by the latest developments of science and technology, updated regulations, consumer preferences, and the growing global demand for affordable and clean energy. 
Yet, many countries face different energy challenges in their pursuit of a low-carbon economy. Utilization of renewable energy sources and energy system digitalization to create more intelligent and flexible energy systems is key to ensuring a smooth energy transition process. A shift towards decentralized energy systems will ensure that everyone can have stable and affordable energy. Mutual partnership to support climate action is required, recognizing the importance of a just transition to a low-carbon economy enabling a fair and just energy transition for many countries. The energy transition system will be efficient and effective if it provides proper energy policy support and financial incentives.

For the third G20 agenda on digital transformation, we have seen how digital technologies have been used to improve projects, products, and service delivery in different industries and to add value. Digital technology is used to manage integrated product whole-life cycles and enhance efficient, reliable, and sustainable business operations. Furthermore, in cities, development is now more sustainable in terms of providing economic resource sharing, autonomous mobility systems, zero-emissions industrial products, recycling materials, and organic food in urban areas, to name a few. We are also using technology to tackle global challenges, including COVID-19 pandemicrelated health improvement and virtual activities. The technologies should be created to support economic and social development goals, including economic, social, health, and education objectives, and environmental sustainability. Digital transformation policies are essential for creating ecosystems for digital growth strategies. The ecosystems should be enhanced by supportive policy design, adequate funding, and program implementation. The transformation policies must provide an adequate technology infrastructure and facilitate skills development.

\section{Advancing Science and Technological Performance}

In this edition of International Journal of Technology (IJTech), we are pleased to present 20 papers dedicated to advancing technology in terms of strengthening scientific research and technological performance and improvement.

The first paper, by M.A. Manzo and J.C. Rodríguez, presents a comparative analysis of the high-performance of design and engineering firms in the aerospace industry of Mexico. The authors argue that absorptive capacity, innovation capacity, entrepreneurial capacity, research and development activities, and specialized human resources are necessary to obtain a high-performance level.

The second paper, by M.H. Al Hazza, A. Abdelwahed, M.Y. Ali, and A.A. Sidek, presents an integrated approach of supplier evaluation and selection using a hybrid multi-criteria decision-making (MCDM) approach. The authors argue that price, rejection rate, online ranking, delivery time, and flexibility are the criteria for effective supplier selection.

The third paper, by K. Chumnumporn, C. Jeenanunta, S. Simpan, K. Srivat, and V. Sanprasert, investigates the role of a leader and the effect of a firm's industry 4.0 technology adoption in Thailand. The authors argue that transformational leadership and external pressure contribute to a firm's adoption of operational technology and information technology.

The fourth paper, by T.W. Pribadi and T. Shinoda, examines the use of hand motion analysis for recognition of qualified and unqualified welders applying 9-DOF IMU sensors and the support vector machine (SVM) approach. The authors argue that the proposed method can be considered to be a cost-effective way to overcome some practical steel construction problems. 
The fifth paper, by P. Naruetharadhol, W.A. Srisathan, N. Gebsombut, P. Wongthahan, and C. Ketkaew, evaluates an open-innovation model in SMEs. The authors argue that the model supports a four-dimensional model incorporating centralization, knowledge management, technology transfer evaluation process, and networks.

The sixth paper, by S. Sulaiman, M. Alajmi, W.N.W. Isahak, M. Yusuf, and M. Sayuti, optimizes cutting parameters and determines the factors significant for the surface roughness quality of aluminum 6061 using the Taguchi method. The authors argue that cutting speed has the greatest effect on surface roughness, followed by feed rate and depth of cut.

The seventh paper, by S. Sugiono, A. Pratomo, and W.S. Nugroho, presents the houseof-quality approach for the design of a minibus to transport visually-impaired and wheelchair-bound passengers. The authors argue that ergonomic design requirements include a wheelchair lift, handrail dimensions, and a hand pole for the blind.

The eighth paper, by R. Woodhead and M.A. Berawi, examines the use of value engineering (VE) to automate inventions in complex technological systems. The authors argue that VE is key to automated invention with Artificial Intelligence (AI) by identifying needed functionality then considering different ways to perform that functionality.

The ninth paper, by M.L. Siregar, T. Tjahjono, and N. Yusuf, predicts the segmentbased effects of heterogeneous traffic and road geometric features on fatal accidents. The authors argue that the speed features of passenger cars and motorcycles require special treatments to reduce the effects on fatal accidents.

The tenth paper, by D.M. Zárate, F. Cárdenas, E.F. Forero, and F.O. Peña, evaluates the strength of concrete through ultrasonic pulse velocity and uniaxial compressive strength. The authors argue that the proposed model can be implemented in devices for measuring ultrasonic pulse velocity in concrete.

The eleventh paper, by W. Partono, M. Irsyam, R. Nazir, M. Asrurifak, and U.C. Sari, evaluates site coefficients and design response spectral acceleration predictions according to the straight-line interpolation method and website software calculations. The authors argue that the largest design response spectral acceleration difference in SD (medium site soil class) between the two methods is less than $0.02 \mathrm{~g}$; for SC (hard) and SE (soft), the difference is less than $0.005 \mathrm{~g}$.

The twelfth paper, written by L. Bekbayeva, E. Negim, R. Niyazbekova, Z. Kaliyeva, G. Yeligbayeva, and J. Khatib, investigates the properties of mortars in the presence of grafted copolymer, including setting time, workability, water absorption, and compressive strength. The authors argue that premixed grafted copolymers with mortar mixes improve the properties of mortar.

The thirteenth paper, by S. Sutijan, S. Wahyudi, M.F. Ismail, P.C.B. Mustika, W. Astuti, A. Prasetya, and H.T.B.M. Petrus, determines the best operating conditions for forward osmosis as a substitute for conventional evaporation methods. The authors argue that the best conditions are obtained at pH 5 with a process temperature of $400^{\circ} \mathrm{C}$.

The fourteenth paper, by B. Sardi, R.F. Ningrum, V.A. Ardiansyah, L. Qadariyah, and M. Mahfud, investigates the effects of catalyst preparation techniques on the yield and quality of liquid biofuel. The authors argue that catalytic slow pyrolysis with different types of catalysts and a variety of catalyst preparation techniques affects the increase in yield and quality adjustment of liquid biofuel.

The fifteenth paper, by F. Murdiya, Y.B. Hendri, A. Hamzah, N. Frimayanti, and A. Amri, discusses few-layer wrinkled graphene (FLwG) that has been synthesized from a coconut shell-based charcoal. The authors argue that that the FLwG formation is mainly led by the 
combination of ionization and deionization of air molecules in a high-temperature and plasma stressing context.

The sixteenth paper, by F. Rahmawati, D.A.N. Romadhona, D.D. Paramita, and W.W. Lestari, investigates the use of a cyclic voltammetry (CV) method to intercalate $\mathrm{Na}+$ into an $\mathrm{FePO}_{4} / \mathrm{Al}$ substrate to produce $\mathrm{NaFePO}_{4} / \mathrm{Al}$ as a potential cathode material. The authors argue the $\mathrm{CV}$ treatment of $\mathrm{FePO}_{4} / \mathrm{Al}$ is more effective than the treatment of the $\mathrm{LiFePO}_{4}$ layer.

The seventeenth paper, by H.A. Mahmood, A.O. Al-Sulttani, N.A. Mousa, and O.H. Attia, investigates the Sultana ignition characteristics of syngas-a diesel fuel with dual-fuel combustion. The authors argue that maximum pressure, temperature, and nitric oxide are obtained by increasing the value of lambda in the chamber of combustion, while the emission of $\mathrm{CO}_{2}$ and $\mathrm{CO}$ decreases inside the engine.

The eighteenth paper, by M.H.N. Aliffrananda, A. Sulisetyono, Y.A. Hermawan, and A. Zubaydi, presents a numerical analysis of floatplane porpoising instability during take-off. The authors argue that longitudinal center of gravity (LCG) near the floater's bow generated a higher heave and pitch porpoising amplitude, with values decreasing after reaching its peak.

The nineteenth paper, by T. Sangkharat and S. Dechjarern, proposes an online thickness measurement system for metal spinning. The authors argue that the thickness from the line laser measurement system is close to the result obtained from measuring the cross-section of the spun part, and the average error of the line laser measurement system is $3.67 \%$.

The last paper, by N. Hendrarini, M. Asvial, and R.F. Sari, presents an optimization of wireless sensor networks with localization-based clustering using a game theory algorithm. The authors argue that the network performance, particularly, the number of data packets sent and the lifetime of the sensor node, tends to increase after the clusterbased localization process begins.

I hope that this edition of IJTech conveys some new insights in the way we conduct our research. I am pleased to accept and respond to any comment or question you may have on the direction and content of IJTech, and I invite you to join us in this venture by sending your work for publication consideration.

With warmest regards from Jakarta,

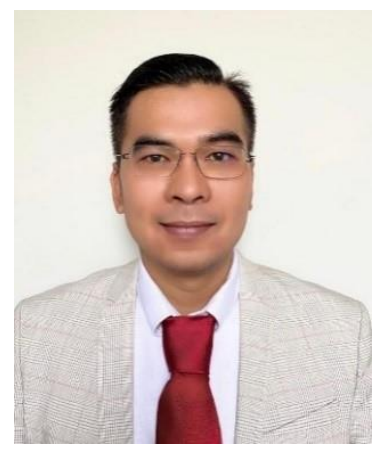

Dr. Mohammed Ali Berawi

Editor in Chief 